\title{
ERRATUM
}

\section{Erratum to: Pirfenidone in Idiopathic Pulmonary Fibrosis: Expert Panel Discussion on the Management of Drug-Related Adverse Events}

\author{
Ulrich Costabel • Elisabeth Bendstrup • Vincent Cottin • Pieter Dewint • Jim J. J. Egan • \\ James Ferguson • Richard Groves • Per M. Hellström • Michael Kreuter • Toby M. Maher • \\ Maria Molina-Molina $\cdot$ Klas Nordlind $\cdot$ Alexandre Sarafidis $\cdot$ Carlo Vancheri
}

To view enhanced content go to www.advancesintherapy.com

Published online: May 8, 2014

(C) Springer Healthcare 2014

Erratum to: Adv Ther

DOI 10.1007/s12325-014-0112-1

The authors of the above-mentioned paper would like to make the following adjustments to their article.

The online version of the original article can be found under doi:10.1007/s12325-014-0112-1.

U. Costabel $(\square)$

Department of Pneumology/Allergology, Ruhrlandklinik, University Hospital, University Duisburg-Essen, Essen, Germany

e-mail: ulrich.costabel@ruhrlandklinik.uk-essen.de

E. Bendstrup

Department of Respiratory Medicine and

Allergology, Aarhus University Hospital, Aarhus,

Denmark

V. Cottin

Hôpital Louis Pradel, Service de Pneumologie,

Centre de Référence National des Maladies

Pulmonaires Rares, Université Claude Bernard Lyon

1, UMR754, Lyon, France

P. Dewint

Department of Gastroenterology and Hepatology,

Erasmus Medical Center, Rotterdam

The Netherlands

J. J. J. Egan

Department of Respiratory Medicine, Mater

Misericordiae University Hospital, Dublin, Ireland
In Table 1 , the value in the Resolved row in the column Diarrhea, Placebo [ $n$ (\%)] currently reads '73 (52)'. This should read '73 (86)'. The correct version of the table is provided below (Table 1). The sentence 'At Week 72, pirfenidone also reduced the proportion of patients with a $50 \mathrm{~m}$ or greater decrement in 6-min walk distance (31\% relative reduction vs.

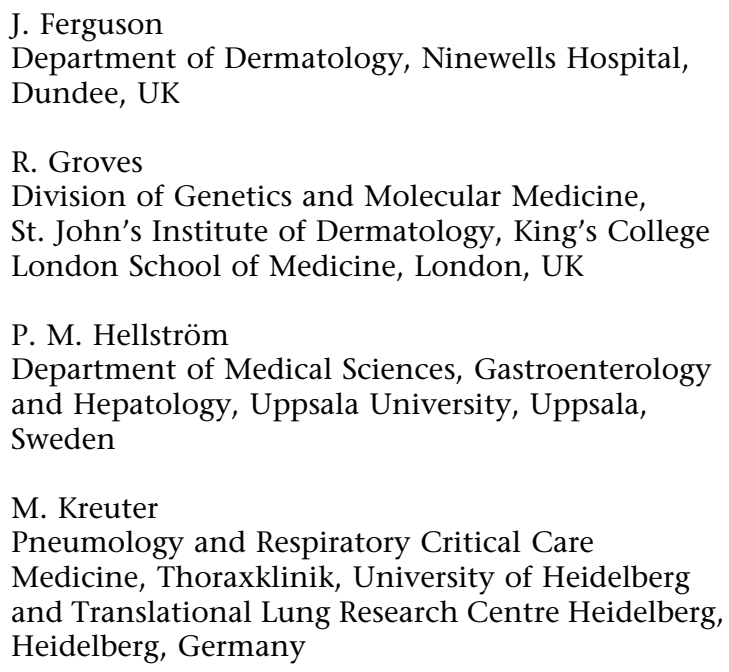
and Hepatology, Uppsala University, Uppsala, Sweden

\section{Kreuter}

Pneumology and Respiratory Critical Care Medicine, Thoraxklinik, University of Heidelberg and Translational Lung Research Centre Heidelberg, Heidelberg, Germany

T. M. Maher

Interstitial Lung Disease Unit, Royal Brompton Hospital, London, UK 
placebo) and...' in the original article should read 'At Week 72, pirfenidone also reduced the proportion of patients with a $50 \mathrm{~m}$ or greater decrement in 6-min walk distance (26\% relative reduction vs. placebo) and...'. The sentence 'Overall, five (1.4\%) and one (0.3\%) pirfenidone patients discontinued therapy due to nausea and vomiting, respectively, and two $(0.6 \%)$ discontinued due to diarrhea' in the original article should read 'Overall, five (1.4\%) and one $(0.3 \%)$ pirfenidone patients discontinued therapy due to nausea and vomiting, respectively, and two $(0.6 \%)$ placebo patients discontinued due to diarrhea'.

M. Molina-Molina

Unidad Funcional de Intersticio Pulmonar, Servicio de Neumología, Hospital Universitario de Bellvitge, IDIBELL, CIBERES, Hospitalet de Llobregat,

Barcelona, Spain

K. Nordlind

Dermatology and Venerology Unit, Department of Medicine, Solna, Karolinska University Hospital, Stockholm, Sweden

A. Sarafidis

Department of Gastroenterology, Parc Leopold

Hospital (CHIREC), Brussels, Belgium

C. Vancheri

Regional Centre for Rare Lung Disease, University of Catania, Catania, Italy

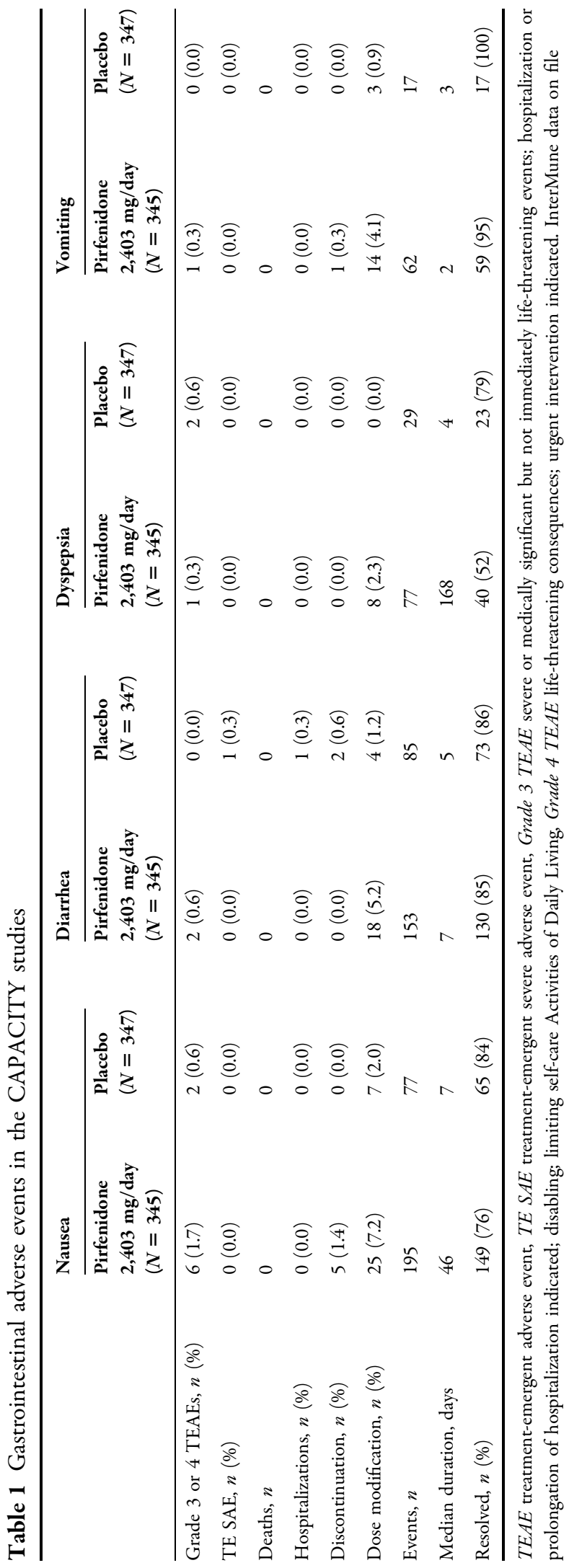

